\title{
Short-term course and prognosis of Crohn's disease
}

\author{
F. T. de DOMBAL, I. L. BURTON, SUSAN E. CLAMP, AND J. C. GOLIGHER \\ From the University Department of Surgery, The General Infirmary, Leeds
}

SUMMARY An analysis is presented of the course and outcome of the initial referred attack in a group of 332 patients with Crohn's disease treated at the General Infirmary at Leeds from 1939 to 1968 inclusive. A further 50 cases were excluded on the basis of insufficient diagnostic evidence: usually such patients had acute terminal ileitis.

Only $5 \%$ of patients achieved full remission on conservative management, and most eventually came to surgery. The overall fatality rate was some $3.3 \%$ and this was affected chiefly by the severity of attack and the age of the patient. The severity of attack was classified as mild, moderate, or severe according to a system which took into account factors such as bowel habit, rectal bleeding, abdominal pain, pulse rate, temperature, haemoglobin, and weight. In attacks graded as 'mild', no deaths occurred; in those graded 'severe' the fatality rate was $8.8 \%$. Similarly, whilst no patient under 20 years of age died, the fatality rate in the over 60 s was some $14.8 \%$.

Further comparison between the present group of 332 patients and an earlier series of 204 patients suffering from ulcerative colitis (Watts, de Dombal, Watkinson, and Goligher, 1966a) shows considerable differences in the course and prognosis of the two diseases. In particular $70 \%$ of patients with ulcerative colitis achieved remission on conservative management alone whereas only $5 \%$ of Crohn's disease patients did so.

These differences, and in particular the poor response to conservative therapy, are discussed, together with their implications for management.

Several writers, notably Van Patter, Bargen, Docherty, Geldman, Mayo, and Waugh (1954), Gump and Lepore (1960), Stahlgren and Ferguson (1961), Schofield (1965), and Edwards (1969) have addressed themselves to the controversial problem of formulating a prognosis for Crohn's disease. But almost without exception they have encountered serious difficulties-from incompleteness of their follow-up data, from the lack of a clear distinction between patients with disease in different sites, or from inadequate definition of the criteria for inclusion of cases or assessment of results. What has further handicapped many of these workers has been their failure to appreciate that, just as in the comparable condition of ulcerative colitis (Edwards and Truelove, 1963, 1964; Watts et al, 1966a and b), the short-term and long-term prognosis for Crohn's disease may be quite different. So, in Crohn's disease it may be important to distinguish between these two concepts of the patient's prognosis. We have elsewhere reported upon the long-term prognosis for Crohn's disease, both after conservative therapy and

Receivod for publication 21 March 1974. operative intervention (Goligher, de Dombal, and Burton, 1971a and b; de Dombal, Burton, and Goligher, 1971a and b; de Dombal, 1972). In this paper we present an analysis of the short-term prognosis for a series of patients, that is to say, their course and outcome during a single attack of Crohn's disease. In each case the attack is that during which the patient was originally referred to this hospital.

\section{Clinical Material and Methods}

According to the records of the Leeds General Infirmary, some 382 patients were seen and treated for Crohn's disease in this hospital up to the year 1969. The first occasion on which such a diagnosis was made was in 1938 so that the time period involved is one of almost precisely 30 years.

ACCEPTANCE OF PATIENTS INTO THE SURVEY Inherent in any retrospective analysis is a danger that in some instances the patient's diagnostic label in the hospital records may have been erroneous. For the purpose of the present survey, therefore, it was decided that patients should only be accepted for 
inclusion if stringent criteria had been met. In this respect we were to some extent fortunate, as there has been something of a bias towards operative therapy for Crohn's disease in this hospital, and also towards resection as opposed to bypass operations. Hence in the vast majority of instances, the diagnosis in our series was made during life on the basis of histopathological evidence of the kind outlined by Morson (1968) and commented upon more recently by Cook and Dixon (1973).

Occasionally patients were accepted into the survey who did not undergo surgical treatment in the Infirmary; most had either biopsy reports showing a compatible histopathological picture, or pathological reports were available from other hospitals where surgery had been carried out. In a handful of instances we felt obliged to accept into the survey patients with extensive disease but for whom no histopathological evidence was available. In these few cases the diagnosis was made during life on the basis of characteristic symptoms and signs, together with negative bacteriological findings and typical radiological appearances of the type outlined by Young (1964).

Applying these criteria to the 382 patients recorded as having been treated for 'Crohn's disease', we found that we were utterly unable to substantiate this diagnosis in some 50 instances. In some of these cases there was positive evidence of an alternative diagnosis but by the time the true diagnosis had become clear the term 'Crohn's disease' had found its way into the hospital records, and this erroneous classification persisted-in some cases for up to 30 years. More often, the patient had 'acute terminal ileitis', and 39 patients were rejected on these grounds. It is therefore necessary before proceeding to the results proper to discuss the concept of acute terminal ileitis and to indicate why such patients have been excluded from the present series.

\section{ACUTE TERMINAL ILEITIS}

We have differentiated between Crohn's disease and acute terminal ileitis, not because the two diseases are necessarily different or because acute terminal ileitis cannot in some instances progress to classical Crohn's disease, but because in most of our cases said to have been acute terminal ileitis we have found insufficient evidence according to the criteria stated for a firm diagnosis of Crohn's disease.

Most patients with acute terminal ileitis were usually diagnosed in the first instance as having appendicitis. They were then subjected to an emergency operation, at which the appendix was found to be normal, but the lower ileum was said to be either congested or thickened by the operating surgeon - often a relatively junior man in training. In accordance with current surgical orthodox practice, no attack was made upon the allegedly inflamed bowel and so no histopathological information became available. Subsequently, the patient experienced no further trouble and radiological investigations revealed no abnormality. This was the course of events in 39 of our patients, and we have felt quite unable in these cases to make a positive diagnosis of Crohn's disease.

But not all our cases initially labelled as acute terminal ileitis pursued this course, for about 15 developed chronic symptoms and a typical radiological picture of Crohn's disease: nine of them underwent a resection for longstanding symptoms, the excised bowel being found on histopathological examination to show typical appearances of Crohn's disease. These cases have been included in our survey since they fulfilled the necessary criteria. Out of a total of 54 patients presenting originally as 'acute terminal ileitis', no more than 15 (or $28 \%$ ) eventually developed 'classical' Crohn's disease after a follow-up period for up to 25 years.

\section{CASES FINALLY ACCEPTED}

Thus, in all, 332 cases were accepted into the series, the final diagnosis of Crohn's disease being made on histopathological grounds in over 300 cases, and on clinical and radiological grounds in the remainder. The composition of this series by sex and age at onset of symptoms is shown in table I and the year of presentation is shown in figure 1, from which it will be seen that the rate of presentation of patients with Crohn's disease to this hospital has increased approximately five-fold in the past three decades. The composition of the series by social class is shown in figure 2, and some of the associated diseases from which the patients suffered up to and including the time of presentation, are shown in figure 3.

In view of recent reports, it is worth noting that all forms of Crohn's disease appear to have increased in frequency, and not merely Crohn's disease in young women or colonic disease in elderly women (Krause, 1971; Kyle, 1972). The distribution by social class

\begin{tabular}{lccc}
\hline Age $(y r)$ & Male & Female & All Patients \\
\hline $0-9$ & 1 & 2 & 3 \\
$10-19$ & 30 & 34 & 64 \\
$20-29$ & 58 & 42 & 100 \\
$30-39$ & 26 & 33 & 59 \\
$40-49$ & 25 & 26 & 51 \\
$50-59$ & 11 & 16 & 27 \\
$60-69$ & 7 & 16 & 23 \\
70 and over & 3 & 2 & 5 \\
Total & 161 & 171 & 332 \\
\hline
\end{tabular}

Table I Composition of series of 332 patients with Crohn's disease by age and sex at onset of symptoms 


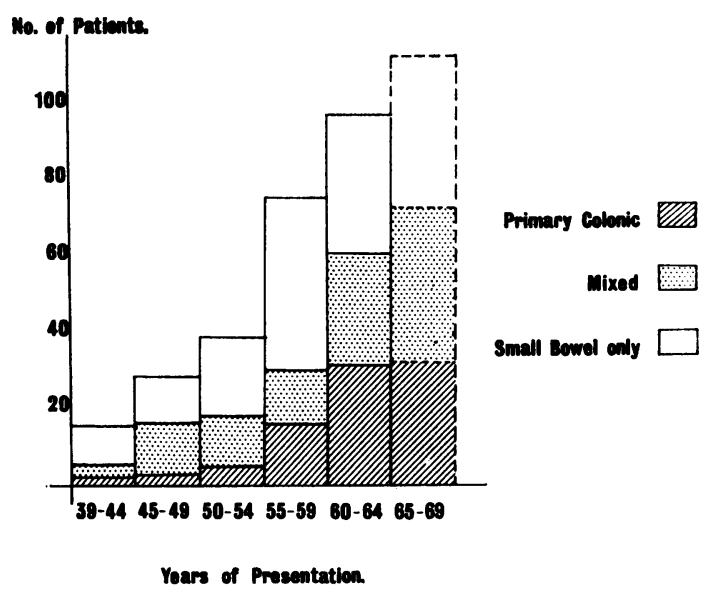

Fig 1 Analysis of series according to time of referral to General Infirmary, Leeds. Note five-fold overall increase and uniformity of distribution between small and large bowel disease.

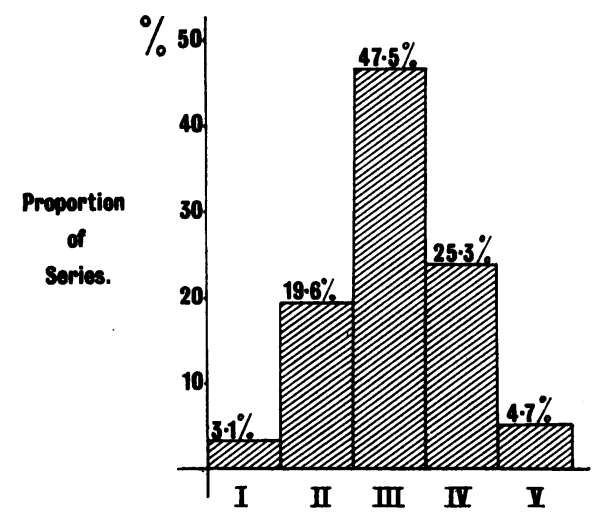

Social Class.

Fig 2 Composition of series by social class.

seems unremarkable, but the associated diseases up to and including presentation are interesting. Particularly noteworthy is the apparently high proportion of patients with peptic ulcer and with 'allergic' disorders such as asthma and eczema. In contrast, only 11 patients were reported to be suffering from any overt psychiatric disorder, only five were known to have gallbladder disease, and only three suffered from diverticular disease.

\section{Findings}

OVERALL OUTCOME OF THE FIRST REFERRED ATTACK

Table II illustrates the overall outcome for all 332

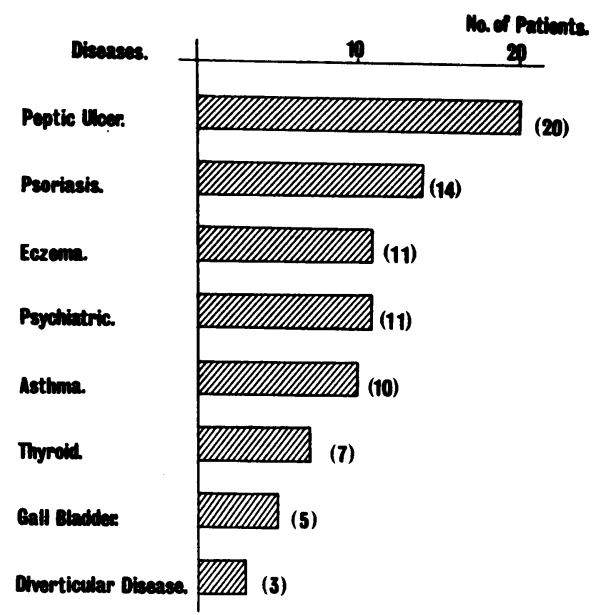

Fig 3 Associated diseases in patients presenting with Crohn's disease.

patients of the attack of Crohn's disease during which they were referred to the General Infirmary at Leeds. Only 17 of the 332 patients $(5.1 \%)$ obtained complete remission of symptoms on conservative management alone. In a further 75 patients $(22.8 \%)$ conservative management was partially successful, for although symptoms referable to Crohn's disease persisted, these were not incapacitating, and the final outcome was generally regarded by the patient as being something of an improvement. In 10 patients $(3.0 \%)$ severe symptoms persisted unabated for a period of one year, at which time, in the absence of any surgical therapy, their 'first referred attack' was said to have resulted in "chronic continuous disease'. Twenty-five patients underwent minor surgery (usually drainage of an abscess or excision of a fistula-in-ano) and all survived.

However, in 199 patients $(60 \%)$, major surgery was employed during the first referred attack, and 10

\begin{tabular}{lrc}
\hline Outcome & No. of Cases \\
\hline Symptoms nil/negative & 17 & $(5 \cdot 1 \%)$ \\
Symptoms (minor) & $75(22.6 \%)$ \\
Symptoms (severe) & 10 & $(3.0 \%)$ \\
Minor surgery (survived) & 25 & $(7.5 \%)$ \\
Major surgery (survived) & $189(56.9 \%)$ \\
Medical death & 1 & $(0.3 \%)$ \\
Surgical death & 10 & $(3.0 \%)$ \\
Total deaths & 11 & $(3.3 \%)$ \\
Unknown & 5 & $(1.5 \%)$ \\
Total & $332(100.0 \%)$ \\
\hline
\end{tabular}

Table II Outcome of first referred attack 


\begin{tabular}{|c|c|c|c|c|c|c|}
\hline \multirow[t]{2}{*}{ Features } & \multicolumn{2}{|l|}{ First Attacks } & \multicolumn{2}{|l|}{ Relapses } & \multicolumn{2}{|l|}{ Total } \\
\hline & No. of Cases & Percentage of Group & No. of Cases & Percentage of Group & No. of Cases & Percentage of Group \\
\hline $\begin{array}{l}\text { Symptoms nil or negligible } \\
\text { Symptoms (not severe) } \\
\text { Severe disease }\end{array}$ & $\begin{array}{l}12 \\
31\end{array}$ & $\begin{array}{r}9 \cdot 2 \\
23 \cdot 7\end{array}$ & $\begin{array}{r}5 \\
44\end{array}$ & $\begin{array}{r}2.5 \\
21.9\end{array}$ & $\begin{array}{l}17 \\
75\end{array}$ & $\begin{array}{r}5 \cdot 1 \\
22 \cdot 6\end{array}$ \\
\hline $\begin{array}{l}\text { (chronic invalid) } \\
\text { Minor surgery (survived) } \\
\text { Major surgery (survived) } \\
\text { Medical death } \\
\text { Surgical death } \\
\text { Unknown }\end{array}$ & $\begin{array}{r}6 \\
12 \\
65 \\
1 \\
3 \\
1\end{array}$ & $\begin{array}{l}4 \cdot 6 \\
9 \cdot 2 \\
49 \cdot 6 \\
.0 \cdot 8\}_{3 \cdot 1} \\
2 \cdot 3\}^{3 \cdot 1} \\
0.8\end{array}$ & $\begin{array}{r}4 \\
13 \\
124 \\
7 \\
7\end{array}$ & $\begin{array}{l}2 \cdot 0 \\
6.5 \\
61 \cdot 7 \\
0.0 \\
3.5\}_{3.5} \\
2.0\end{array}$ & $\begin{array}{r}10 \\
25 \\
189 \\
1 \\
10 \\
5\end{array}$ & $\begin{array}{l}3.0 \\
7.5 \\
56.9 \\
0.3 \\
3.0 \\
1.5\end{array}$ \\
\hline Total & 131 & $100 \cdot 0$ & 201 & $100 \cdot 0$ & 332 & $100 \cdot 0$ \\
\hline
\end{tabular}

Table III Outcome of first referred attack

of these patients died in the early postoperative period, an operative mortality of roughly $5 \%$. In a further five patients the precise outcome of the first referred attack was unknown although it was known that they neither came to surgery nor died during this attack.

\section{FIRST ATTACK CASES COMPARED WITH}

RELAPSED

It might reasonably be expected that some bias would be introduced into these overall results by the 'relapse' group of patients, that is to say, those who were referred here after treatment elsewhere had failed. Table III therefore analyses the overall results according to whether the patients concerned were referred to the General Infirmary in the initial attack of disease or referred here in a subsequent relapse.

Surprisingly, not a great deal of difference emerges when such a comparison is made. The rate of recourse to surgery is somewhat higher in the relapse group, indicating perhaps some patients who were referred to this hospital specifically for surgery, but the death rates, overall and for the early postoperative period, are comparable. Moreover, it is noteworthy that, even when cases presenting de novo are considered, only some $9 \%$ achieved a full remission of symptoms on conservative management alone. This finding is rather a surprising one, and is in quite marked contrast to the situation obtaining with ulcerative colitis. Nevertheless, it implies that it is not unreasonable to combine (for the purposes of further analysis) these two groups of patients.

\section{FACTORS GOVERNING OUTCOME OF THE FIRST ATTACK}

\section{Severity of disease}

In assessing the severity of Crohn's disease, we were somewhat handicapped by the lack of any preexisting classification of severity, such as that put forward by Truelove and Witts (1955) when considering ulcerative colitis. Using Truelove and Witts' philosophy as a basis, we therefore devised a comparable classification for Crohn's disease, the elements of which are illustrated in table IV. Under this system the first referred attack of Crohn's disease was graded as 'mild' in 51 patients, 'moderate' in 171 patients, and 'severe' in 102 patients.

Table $\mathrm{V}$ and figure 2 show the outcome of the first referred attack according to the classification of the patients into these three groups. Of particular interest is the death rate during the initial attack. None of the patients with mild disease died, $1.2 \%$ of those with moderate symptoms eventually died, and

\begin{tabular}{|c|c|c|}
\hline \multirow[t]{2}{*}{ Features } & \multicolumn{2}{|c|}{ Severity of Attack ${ }^{1}$} \\
\hline & Mild & Severe \\
\hline $\begin{array}{l}\text { Local } \\
\text { Bowel actions } \\
\text { Pain } \\
\text { Rectal bleeding }\end{array}$ & $\begin{array}{l}2-3 / \text { day } \\
\text { Occasional/mild } \\
\text { Negligible }\end{array}$ & $\begin{array}{l}6 \text { or more/day } \\
\text { Continuous/severe } \\
\text { Macroscopic blood in stools }\end{array}$ \\
\hline $\begin{array}{l}\text { Systemic } \\
\text { Pulse rate } \\
\text { Temperature } \\
\text { Haemoglobin } \\
\text { Weight loss }\end{array}$ & $\begin{array}{l}<90 / \text { min } \\
<99^{\circ} \mathrm{F} \\
>80 \% \\
<\frac{1}{8} \text { stone }\end{array}$ & $\begin{array}{l}>100 / \min \\
>100^{\circ} \mathrm{F} \\
<70 \% \\
>1 \text { stone }\end{array}$ \\
\hline
\end{tabular}

Table IV Classification of severity in attacks of Crohn's disease (modified from Truelove and Witts, 1955)

'Attacks intermediate in severity graded as 'moderate'. 
Severity of Disease.

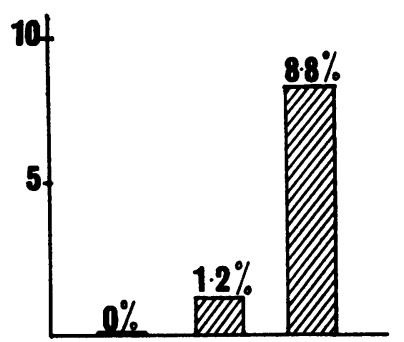

inld Moderate Sovere
Site of Disease.

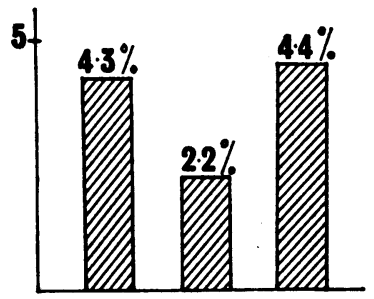

Large Small Mixed
Fig 4 Factors affecting mortality in initial attack of Crohn's disease. Figures indicate percentage mortality in each group.
Age of Patient.

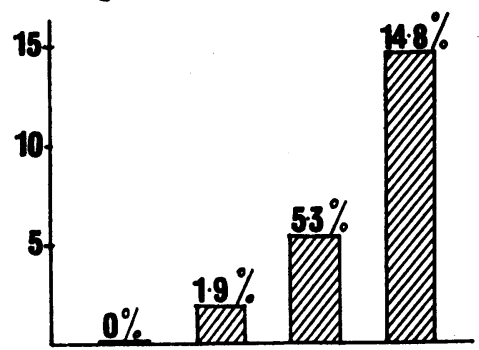

$<20 \quad 20-39 \quad 40-59 \quad 60+$
Sex of Patient.

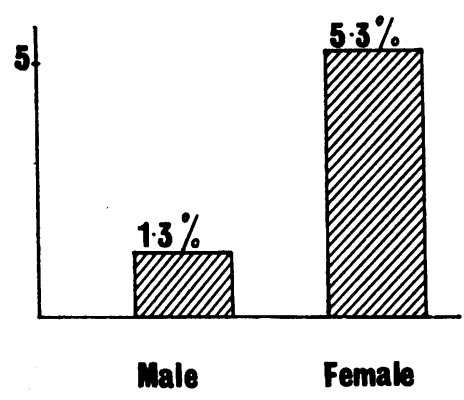

\begin{tabular}{|c|c|c|c|}
\hline \multirow[t]{2}{*}{ Features } & \multicolumn{3}{|c|}{ All Patients } \\
\hline & $\begin{array}{l}\text { Mild } \\
\text { (\% of } 51 \text { ) }\end{array}$ & $\begin{array}{l}\text { Moderate } \\
\text { (\% of 171) }\end{array}$ & $\begin{array}{l}\text { Severe } \\
\text { (\% of } 102)\end{array}$ \\
\hline $\begin{array}{l}\text { Symptoms nil/negative } \\
\text { Symptoms minor } \\
\text { Symptoms severe } \\
\text { Minor surgery } \\
\text { Major surgery } \\
\text { Medical death } \\
\text { Surgical death } \\
\text { All deaths }\end{array}$ & $\begin{array}{l}15 \cdot 7 \\
43 \cdot 1 \\
\overline{29 \cdot 4} \\
11 \cdot 8 \\
= \\
=\end{array}$ & $\begin{array}{r}1 \cdot 8 \\
24 \cdot 6 \\
2 \cdot 3 \\
4 \cdot 1 \\
65 \cdot 4 \\
1 \cdot 7 \\
1 \cdot 2\end{array}$ & $\begin{array}{r}4 \cdot 9 \\
10 \cdot 8 \\
5 \cdot 9 \\
2 \cdot 9 \\
66 \cdot 7 \\
1 \cdot 0 \\
10 \cdot 5 \\
8 \cdot 8\end{array}$ \\
\hline
\end{tabular}

Table V Outcome of first referred attack related to its severity

$8.8 \%$ of those with severe attacks succumbed, the postoperative mortality in this last group being no less than $10.5 \%$. As regards the efficacy of conservative management, $59 \%$ of patients having mild attacks were somewhat improved by this means, but the comparable figure for patients in severe attacks was a mere $15 \%$.

Site of disease

Crohn's disease may affect any part of the gastro- intestinal tract as well as selected sites elsewhere on infrequent occasions. To have adopted a highly selective classification of this variable, as was done in our previous studies of ulcerative colitis (Watts et al, 1966a), would have resulted in many different categories of cases each with few patients so making statistical analysis of the results difficult. We have chosen, therefore, to group our patients merely according to whether the disease was in the large bowel, in the small bowel, or in both sites. The results of this subdivision are shown in table VI and figure 4.

Seventy patients were known to have disease confined to the large bowel at the time of initial presentation, in 136 the disease process was completely restricted to the small intestine, and in 115 the disease involved both large and small bowel. Conservative management proved most effective in patients with disease restricted to the large bowel. Over $10 \%$ of these patients achieved full clinical remission of symptoms, only $2.9 \%$ progressed to chronic invalidism, and the rate of recourse to surgery was relatively low, though even so it was almost $50 \%$. 


\begin{tabular}{|c|c|c|c|}
\hline Features & $\begin{array}{l}\text { Large } \\
\text { ( \% of } 70 \\
\text { patients) }\end{array}$ & $\begin{array}{l}\text { Small } \\
(\% \text { of } 136 \\
\text { patients })\end{array}$ & $\begin{array}{l}\text { Mixed } \\
\text { (\% of } 115 \\
\text { patients) }\end{array}$ \\
\hline $\begin{array}{l}\text { Symptoms nil or negligible } \\
\text { Symptoms (not severe) } \\
\text { Severe disease }\end{array}$ & $\begin{array}{l}11 \cdot 4 \\
24 \cdot 3\end{array}$ & $\begin{array}{r}5.9 \\
22.0\end{array}$ & $\begin{array}{r}0.9 \\
22.6\end{array}$ \\
\hline (chronic invalid) & 2.9 & 0.7 & $6 \cdot 1$ \\
\hline Minor surgery (survived) & $10 \cdot 0$ & $10 \cdot 3$ & 1.7 \\
\hline Major surgery (survived) & $47 \cdot 1$ & $\mathbf{5 8 . 0}$ & $64 \cdot 3$ \\
\hline Death & $4 \cdot 3$ & $2 \cdot 2$ & 4.4 \\
\hline
\end{tabular}

Table VI Outcome of first referred attack related to site of disease excluding 11 patients with either extent or outcome unknown

These achievements of conservative therapy may not appear particularly spectacular, but they are impressive when compared with the results of conservative management for patients with diffuse disease affecting both small and large bowel. In this latter group, only one patient out of 115 achieved a full remission of symptoms on conservative treatment alone, and the overwhelming majority eventually came to surgery.

\section{Age of the patient}

The age of the patient had a profound effect upon the outcome of the first referred attack, as shown in table VII. Particularly striking are the death rates in the varying age groups analysed (fig 4). No patient under the age of 20 died during an initial attack, but thereafter the mortality rose steeply, from $1.9 \%$ overall in the age group 20-39, through $5.3 \%$ in the age group $40-59$ years, to no less than $14.8 \%$ in the group of patients aged 60 years and over at the time of their first referred attack. Moreover, this trend holds good not only for the whole group surveyed, but also for patients in their first attack when considered separately. We must, therefore, conclude that, as with other diseases such as ulcerative colitis (Watts et al, 1966a, b) and haematemesis (Jones, 1950), an acute attack of Crohn's disease presents increased dangers in the elderly patient.

Sex of the patient

Surprisingly, the mortality rate during the initial referred attack proved to be higher in females $(5.3 \%)$ than in males $(1.3 \%)$ as shown in figure 4 . This difference, when analysed statistically, reaches significance at the $5 \%$ level $(P<0.05)$ and is consistently seen in both first attack and relapse cases. We can offer no explanation for this finding, nor for the concomitant finding that the rate of progression to chronic invalidism is also significantly higher in females than in males $(5.3 \%$ vs $0.6 \%$, $P<0.02$ ).

\section{Rapidity of onset}

Previous work (Atwell, Duthie, and Goligher, 1965) has suggested that the rapidity of onset might to some extent govern the outcome of Crohn's disease. The present study does not answer this question as regards the long term, but it is clear from table VIII that rapidity of onset has very little overall effect upon the outcome of the immediate attack of Crohn's disease. Although the death rate in patients during their first attack is higher amongst those with a gradual onset, this difference is not significant, and is counterbalanced by a trend in precisely the opposite direction amongst patients presenting in a relapse of established Crohn's disease. Thus the overall death rates are almost identical $(3.5 \%$ vs $2.9 \%)$ in the two groups.

The most likely explanation for this change in our observations lies with the exclusion from the present series of cases presenting with 'acute terminal

\begin{tabular}{lcc}
\hline Features & \multicolumn{2}{c}{ All Patients } \\
\cline { 2 - 3 } & $\begin{array}{l}\text { Rapid } \\
(\% \text { of } 225)\end{array}$ & $\begin{array}{l}\text { Gradual } \\
(\% \text { of } 102)\end{array}$ \\
\hline Symptoms nil/negative & 4.4 & 6.9 \\
Symptoms minor & 24.9 & 17.6 \\
Severe disease & 2.7 & 3.9 \\
Minor surgery & 6.2 & 10.8 \\
Major surgery & 58.2 & 56.9 \\
Medical death & $-5.8\}^{3.5}$ & $1.0\}^{2.9}$ \\
Surgical death & $3.3\}^{2.9}$ & \\
\hline
\end{tabular}

Table VIII Outcome of first attack related to rapidity of onset ${ }^{1}$

${ }^{1}$ Excludes five patients in whom rapidity and outcome are unknown.

\begin{tabular}{|c|c|c|c|c|}
\hline \multirow[t]{2}{*}{ Features } & \multicolumn{4}{|c|}{ All Patients Aged (yr) } \\
\hline & $<20(\%$ of 67$)$ & $20-39(\%$ of 157$)$ & $40-59(\%$ of 75$)$ & $60+(\%$ of 27$)$ \\
\hline $\begin{array}{l}\text { Symptoms nil/negative } \\
\text { Symptoms minor } \\
\text { Symptoms severe } \\
\text { Minor surgery } \\
\text { Major surgery } \\
\text { Medical death } \\
\text { Surgical death } \\
\text { All deaths }\end{array}$ & $\begin{array}{r}2 \cdot 9 \\
21 \cdot 7 \\
4 \cdot 3 \\
11 \cdot 6 \\
59 \cdot 4 \\
= \\
=\end{array}$ & \begin{tabular}{r|}
$6 \cdot 4$ \\
$24 \cdot 2$ \\
$3 \cdot 2$ \\
$7 \cdot 6$ \\
$56 \cdot 7$ \\
$3 \cdot 3$ \\
$1 \cdot 9$
\end{tabular} & $\begin{array}{r}2 \cdot 7 \\
26 \cdot 7 \\
1 \cdot 3 \\
5 \cdot 3 \\
58 \cdot 7 \\
8 \cdot 3 \\
8 \cdot 3 \\
5 \cdot 3\end{array}$ & $\begin{array}{r}11 \cdot 1 \\
7 \cdot 4 \\
3 \cdot 7 \\
3 \cdot 7 \\
35 \cdot 7 \\
55 \cdot 5 \\
3.7 \\
16 \cdot 7 \\
14 \cdot 8\end{array}$ \\
\hline
\end{tabular}

Table VII Age related to outcome of first referred attack 
ileitis'. As already discussed, the prognosis of such cases is excellent, but in many instances there is no positive evidence that the patient does in fact have Crohn's disease; and it seems most likely that inclusion of such patients in previous surveys has been the factor which appeared to confer a favourable prognosis on patients with a rapid onset of Crohn's disease.

\section{Discussion}

Of the several problems brought to light by this study, three seem to warrant particular consideration, namely, (1) the criteria for acceptance of patients into such an enquiry; (2) the relatively disappointing results of conservative management; and (3) the comparison of our present findings as regards Crohn's disease with our earlier findings in ulcerative colitis.

WHAT CONSTITUTES 'CROHN'S DISEASE?' One possible criticism of the present study concerns the criteria by which patients were selected for admission to this series. We have been extremely rigorous in rejecting patients who did not present clear evidence, mainly of a histopathological nature, that they were in fact suffering from Crohn's disease, and in particular we have excluded a number of patients with acute terminal ileitis, whom others, including Crohn (1965) himself, would undoubtedly have included. It could thus be argued with some justification that our own survey is not representative of Crohn's disease as a whole.

We would defend our own decision to exclude these patients upon three main grounds. First, the diagnosis in such cases is often tenuous in the extreme and in a fair proportion ( $22 \%$ ) of patients the diagnosis eventually proved to be erroneous as some other unrelated cause was later discovered for their symptoms, such as a bleeding ovarian cyst causing serosal inflammation of an adherent terminal ileum. Second, even if cases with 'typical' acute terminal ileitis are considered, their natural history is quite different from that of the cases described in this series. Thus, even if they had been included for analysis, they would have rapidly been separated off from the main group of patients. Finally, and far more important, it seemed to us obligatory at this stage of our knowledge of Crohn's disease to consider only those patients for whom we could define positive objective grounds on which the diagnosis of Crohn's disease was made during life. Accordingly this is what was done, and this policy is in line with that of several other workers(Strömbeck, 1937; Homb, 1946; Armitage and Wilson, 1950;
Austin, 1956; Jørgensen, Varg, and Pedersen, 1969; Sjöström, 1971).

\section{THE OUTCOME OF CONSERVATIVE MANAGEMENT}

Truelove (1971) has aptly commented that the whole question of the medical management of Crohn's disease at the present time is in a state of utter confusion. The results of this confusion are well seen in the present survey, for, whatever the successes or failures of operative intervention (see de Dombal et al, 1971a, b) there can be little doubt from our results in this survey that conservative forms of therapy have had little or no effect upon the patient. It could be argued that there has been a bias towards surgical intervention in this hospital, and that some of the patients who came to surgery might eventually have achieved remission on medical treatment alone. Conceivably, this might be so, but there are several reasons for rejecting this argument. First, there is no evidence to indicate that increasing the duration of conservative management increases its efficacy. Second, the long-term results of conservative management for Crohn's disease in our own series are equally unimpressive. Finally, in patients with diffuse disease (where operation tends to be delayed because of anticipated technical difficulties and fear of postoperative malabsorption) the results of conservative management are lamentable in the extreme. Only one single patient out of over one hundred with diffuse lesions achieved even a temporary return to normal health on conservative management alone (table VIII).

\section{COMPARISON WITH ULCERATIVE COLITIS}

From these data it is apparent that the natural history of the first referred attack of Crohn's disease is completely different from that of ulcerative colitis as reported from Oxford (Edwards and Truelove, 1963) and from our earlier studies in Leeds (Watts et al, 1966a). Table IX shows that whilst $70 \%$ of patients suffering from an initial attack of ulcerative colitis may expect to achieve remission of symptoms on conservative management, the comparable figure for Crohn's disease is only $5.1 \%$. Moreover the rate of recourse to radical surgery is far higher in Crohn's disease $(56.9 \%)$ than in ulcerative colitis $(11.3 \%)$.

It might well be argued that this comparison of our overall findings in Crohn's disease against a group of ulcerative colitis patients is invalid. We, therefore, undertook a further analysis, restricting consideration to Crohn's disease patients who presented in the initial attack and in whom disease was wholly restricted to the large bowel. The results of this further analysis are shown in table $X$ from which it will be seen that the rate of recourse to surgery is still 


\begin{tabular}{llc}
\hline Features & $\begin{array}{l}\text { Ulcerative Colitis' } \\
\text { (204 patients) }\end{array}$ & $\begin{array}{c}\text { Crohn's Disease } \\
\text { (332 patients) }\end{array}$ \\
\hline Remission & 70.1 & 5.1 \\
Minor symptoms & 16.2 & 22.6 \\
Chronic invalid & 1.0 & 3.0 \\
Minor surgery & -1.3 & 7.5 \\
Radical surgery & 11.3 & 56.9 \\
Death & 3.9 & 3.3 \\
\hline
\end{tabular}

Table IX Outcome of first referred attack of ulcerative colitis related to Crohn's disease

${ }^{1}$ Results exclude other and unknown cases

'From Watts et al, 1966a.

far higher in Crohn's disease and the proportion of patients undergoing full remission on conservative management is still disappointingly low. It might also be argued that Crohn's disease of the colon is predominantly found in the elderly patient (Kyle, 1972) but in fact a comparison between age at onset and site of onset, or indeed maximum extent of disease in the present series (table XI), shows surprisingly little relationship between these two features.

Finally, some authorities, notably Bargen (1966), have argued that the distinction between colonic Crohn's disease and ulcerative colitis is an academic one of relatively little practical importance. Table X casts considerable doubt upon that assertion for it shows that in the short term alone the natural history of the two conditions is entirely different. Such findings lend an added impetus to the attempts by Spicer and his colleagues (1973) and to our own

\begin{tabular}{lll}
\hline Features & $\begin{array}{l}\text { Ulcerative Colitis } \\
\text { (204 patients) }\end{array}$ & $\begin{array}{l}\text { Crohn's Disease } \\
\text { (70 patients) }\end{array}$ \\
\hline Remission & $70 \cdot 1$ & 11.4 \\
Minor symptoms & 16.2 & $24 \cdot 3$ \\
Chronic invalid & 1.0 & 2.9 \\
Minor surgery & - & $10 \cdot 0$ \\
Radical surgery & $11 \cdot 3$ & 47.1 \\
Death & 3.9 & 4.3 \\
\hline
\end{tabular}

Table X Outcome of first referred attack in cases of Crohn's disease of the large bowel related to ulcerative colitis

${ }^{1}$ From Watts et al (1966a)

\begin{tabular}{lccc}
\hline Age at Onset $(y r)$ & \multicolumn{4}{l}{ Extent of Disease } \\
\cline { 2 - 4 } & Large & Small & Mixed \\
\hline $0-19$ & 7 & 21 & 39 \\
$20-39$ & 23 & 43 & 85 \\
$40-59$ & 14 & 33 & 30 \\
60 and over & 10 & 8 & 8 \\
\hline
\end{tabular}

Table XI Comparison of age at onset of symptoms compared with maximum extent of disease in $\mathbf{3 3 2}$ patients ${ }^{1}$

'Excluding 16 patients with 'other' or 'unknown' extent of disease. computer-assisted studies (de Dombal et al, 1974) to differentiate more clearly between the two conditions.

We thank the surgeons and physicians of the General Infirmary for permission to study their patients. One of us (I.L.B.) was assisted by a grant from the Board of Governors of the Infirmary, which we also acknowledge with gratitude.

References

Armitage, G., and Wilson, M. (1950). Crohn's disease: a survey of the literature and a report on 34 cases. Brit. J. Surg., 38, 182-193.

Atwell, J., Duthie, H. L., and Goligher, J. C. (1965). The outcome of Crohn's disease. Brit. J. Surg., 52, 966.

Austin, W. E. (1956). Acute regional ileitis. Canad. med. Ass. J., 74, 289-290.

Bargen, J. A. (1966). Panel discussion. In 'Symposium on newer biological concepts in ulcerative colitis and related diseases'. Gastroenterology, 51, 806-809.

Cook, M. G., and Dixon, M. C. (1973). An analysis of the reliability of detection and diagnostic value of various pathological features in Crohn's disease and ulcerative colitis. Gut, 14, 255-262.

Crohn, B. B. (1965). In 'Panel Discussion on regional enterocolitis'. Dis. Colon Rect., 8, 3.

de Dombal, F. T. (1972). The results of surgical treatment for Crohn's disease. Brit. J. Surg., 59, 826-829.

de Dombal, F. T., Burton, I., and Goligher, J. C. (1971a). The early and late results of surgical treatment for Crohn's disease. Brit. J. Surg., 58, 805-816.

de Dombal, F. T., Burton, I., and Goligher, J. C. (1971a). Recurrence of Crohn's disease after primary excisional surgery. Gut, 12, 519-527.

de Dombal, F. T., Leaper, D. J., Horrocks, J. C., Staniland, J. R., Clamp, Susan E., and McCann, A. P. (1974). Human and computer aided diagnosis of lower gastro-intestinal disorders. (In preparation).

Edwards, F. C., and Truelove, S. C. (1963). The course and prognosis of ulcerative colitis. Pts I and II. Gut, 4, 299-315.

Edwards, F. C., and Truelove, S. C. (1964). The course and prognosis of ulcerative coiltis. Pts III and IV. Gut, 5, 1-21.

Edwards, H. (1969). Crohn's Disease: an inquiry into its nature and consequences. Ann. roy. Coll. Surg. Engl., 44, 121-139.

Goligher, J. C., de Dombal, F. T., and Burton, I. (1971a). Surgical treatment and its results. In Regional-Enteritis (Crohn's disease), edited by A. Engel and T. Larsson (Skandia International Symposia, V), pp. 166-176. Nordiska Bokhandels, Stockholm.

Goligher, J. C., de Dombal, F. T., and Burton, I. (1971b). Crohn's disease with special reference to its surgical management. Progr. Surg., 10, 1-21.

Gump, F., and Lepore, M. J. (1960). Prognosis in acute and chronic regional enteritis, Gastroenterology, 39, 694-701.

Homb, A. (1946). On acute regional enteritis. Acta chir. scand., 94, 343-361.

Jones, F. A. (1950). Haematemesis and malaena with specific reference to bleeding peptic ulcer. Brit. med. J., 2, 441-447.

Jørgensen, T. G., Vang, O., and Pedersen, O. (1969). Tre og Tredive patienter med akut terminal ileitis opereret pá mistanke one appendicitis og fulgt 5-22 ár. Nord. med., 82, 1415-1418.

Krause, U. (1971). Epidemiology of Crohn's disease in Sweden. In Regional-Enteritis (Crohn's disease), edited by A. Engel and T. Larsson (Skandia International Symposia, V), pp. 142-152. Nordiska Bokhandels, Stockholm.

Kyle, J. (1971). An epidemiological study of Crohn's disease in North East Scotland. Gastroenterology, 61, 826-833.

Morson, B. C. (1968). In Ulcerative Colitis, edited by J. C. Goligher, F. T. de Dombal, J. M. Watts, and G. Watkinson, ch. 2, pp. 26-27. Bailliere, Tindall, and Cassell, London.

Schofield, P. F. (1965). The natural history and treatment of Crohn's disease. Ann. roy. Coll. Surg. Engl., 36, 258-265.

Sjöström, B. (1971). Acute terminal ileitis and its relation to Crohn's disease. In Regional-Enteritis (Crohn's disease), edited by 
A. Engel and T. Larsson (Skandia International Symposia, V), pp. 73-76. Nordiska Bokhandels, Stockholm.

Spicer, C. C., Jones, J. H., and Lennard-Jones, J. E. (1973). Discriminant and Bayes analysis in the differential diagnosis of Crohn's disease and proctocolitis. Meth. Inf. Med., 12, 118-122.

Stahlgren, L. H., and Ferguson, L. K. (1961). The results of surgical treatment of chronic regional enteritis. J. Amer. med. Ass., 175, 986-989.

Strömbeck, J. P. (1937). Ileitis terminalis. Acta chir. scand., Suppl. 80, $1-59$.

Truelove, S. C. (1970). Personal communication.

Truelove, S. C., and Witts, L. J. (1955). Cortisone in ulcerative colitis: final report on a therapeutic trial. Brit. med. J., 2, 1041-1044.

Van Patter, W. N., Bargen, J. A., Dockerty, M. B., Geldman, W. H., Mayo, C. W., and Waugh, J. M. (1954). Regional enteritis. Gastroenterology, 26, 347-450.

Watts, J. M., de Dombal, F. T., Watkinson, G., and Goligher, J. C. (1966a). The early course of ulcerative colitis. Gut, 7, 16-29.

Watts, J. M., de Dombal, F. T., Watkinson, G., and Goligher, J. C., (1966b). The long term prognosis of ulcerative colitis. Brit. med. J., 1, 1447-1453.

Young, A. C. (1964). Radiology of Crohn's disease of the large intestine. (Abstr.) Gut, 5, 205. 